\title{
Invasive species cause large-scale loss of native California oyster habitat by disrupting trophic cascades
}

\author{
David L. Kimbro • Edwin D. Grosholz • Adam J. Baukus • Nicholas J. Nesbitt • \\ Nicole M. Travis $\cdot$ Sarikka Attoe $\cdot$ Caitlin Coleman-Hulbert
}

Received: 26 November 2008 / Accepted: 27 February 2009 / Published online: 8 April 2009

(C) The Author(s) 2009. This article is published with open access at Springerlink.com

\begin{abstract}
Although invasive species often resemble their native counterparts, differences in their foraging and antipredator strategies may disrupt native food webs. In a California estuary, we showed that regions dominated by native crabs and native whelks have low mortality of native oysters (the basal prey), while regions dominated by invasive crabs and invasive whelks have high oyster mortality and are consequently losing a biologically diverse habitat. Using field experiments, we demonstrated that the invasive whelk's distribution is causally related to a large-scale pattern of oyster mortality. To determine whether predatorprey interactions between crabs (top predators) and whelks (intermediate consumers) indirectly control the pattern of oyster mortality, we manipulated the presence and invasion status of the intermediate and top trophic levels in labora-
\end{abstract}

Communicated by Geoffrey Trussell.

Electronic supplementary material The online version of this article (doi:10.1007/s00442-009-1322-0) contains supplementary material, which is available to authorized users.

D. L. Kimbro - E. D. Grosholz · S. Attoe - C. Coleman-Hulbert Department of Environmental Science and Policy,

University of California at Davis,

Davis, CA 95616, USA

e-mail: tedgrosholz@ucdavis.edu

\section{S. Attoe}

e-mail: sarikka.attoe@gmail.com

C. Coleman-Hulbert

e-mail: caitlinch@gmail.com

D. L. Kimbro · A. J. Baukus · N. J. Nesbitt · N. M. Travis

Bodega Marine Laboratory, P.O. Box 247,

Bodega Bay, CA 94923, USA

e-mail: bauk27@hotmail.com tory mesocosms. Our results show that native crabs indirectly maintain a portion of the estuary's oyster habitat by both consuming native whelks (density-mediated trophic cascade) and altering their foraging behavior (trait-mediated trophic cascade). In contrast, invasive whelks are naive to crab predators and fail to avoid them, thereby inhibiting trait-mediated cascades and their invasion into areas with native crabs. Similarly, when native crabs are replaced with invasive crabs, the naive foraging strategy and smaller size of invasive crabs prevents them from efficiently consuming adult whelks, thereby inhibiting strong density-mediated cascades. Thus, while trophic cascades allow native crabs, whelks, and oysters to locally co-exist, the replacement of native crabs and whelks by functionally similar invasive species results in severe depletion of native oysters. As 
coastal systems become increasingly invaded, the mismatch of evolutionarily based strategies among predators and prey may lead to further losses of critical habitat that support marine biodiversity and ecosystem function.

Keywords Olympia oyster Ostreola conchaphila . Trait-mediated indirect interaction · Foundation species . Carcinus maenas $\cdot$ Whelks

\section{Introduction}

Trophic cascades indirectly maintain many important basal species including hardwood trees, kelps, salt-marsh plants, and scallops (Estes and Palmisano 1974; Myers et al. 2007; Ripple and Beschta 2007; Silliman and Bertness 2002) when top predators reduce the foraging of intermediate consumers, either by eating them (Carpenter et al. 1985; Hairston et al. 1960; Paine 1980) or by altering their behavior (Abrams 1995; Preisser et al. 2005; Trussell et al. 2002). Although trophic cascades require that top predators be present, predator presence-alone-may not always be sufficient (Schmitz et al. 2004; Werner and Peacor 2003). For example, in density-mediated cascades, a top predator must frequently select an intermediate consumer that is capable of depleting basal species, and these predator-prey encounters must result in enough mortality or predation efficiency (Vermeij 1982b) to reduce the population of an intermediate consumer (Hairston et al. 1960; Strong 1992). In trait-mediated cascades, cues of the top predator (e.g., hunting strategy sensu Schmitz et al. 2004) must be recognized by and cause the intermediate consumer to spend more time and energy hiding rather than consuming basal species (Abrams 1995; Werner and Peacor 2003). Thus, trophic cascades ultimately depend on the appropriate matching of strategies or traits between predator and prey (Schmitz et al. 2004).

While these previous studies have refined our understanding of trophic cascades, the ongoing movement of species beyond their natural ranges has increasingly brought together invasive and native species that historically interacted with different predators and prey (Ruiz et al. 2000; Sax and Gaines 2003). Because this historical exposure may influence the degree of match between predator-prey types (Strauss et al. 2008; Vermeij 2001), invaders may interfere with or fail to recreate historically important native trophic cascades. For instance, a nonnative intermediate consumer may not participate in a trait-mediated cascade if it is unable to recognize or effectively respond to a native top predator (Cox and Lima 2006; Werner and Peacor 2003). This naivete may occur because the intermediate consumer experienced little predation or sufficiently different predators in its native range and thereby employs an inappropriate anti-predator strategy, ultimately leading to an unsuccessful invasion (Cox and Lima 2006). Naivete, however, could also weaken density-mediated cascades and promote invasion when the foraging traits of top predators are not well matched to a novel intermediate consumer; such predators may choose or only be able to eat small numbers of a novel intermediate consumer. In this case, the release of the intermediate consumer from population control could threaten important basal species including key, habitatproviding foundation species (Stachowicz 2001). Thus, the failure to fit into existing trophic cascades may be an important and underappreciated mechanism by which invasive species affect the organization and diversity of native food webs.

In this study, we investigated whether replacing a native top predator (crab; Fig. 1a) and native intermediate consumer (whelk; Fig. 1b) with functionally similar invasive species sufficiently alters established trophic cascades to explain why the invaded portion of a California estuary is losing a historically abundant basal species (the non-commercial and native Olympia oyster, Ostreola conchaphila; Fig. 1c, d; see Electronic Supplementary Material S1-S5 for map of study site, methods, and data underlying Fig. 1). Our research and findings can be divided into four parts.

First, we manipulated the density of an invasive intermediate consumer (whelk) in the field to test whether this invasion can directly account for oyster mortality being greater (Fig. 1c) and oyster densities being fewer (Fig. 1d) in invaded areas of the estuary. We found that the oyster mortality was positively correlated with invasive whelk density. We also found that oyster mortality could not be explained by desiccation stress, water temperature, or salinity.

Second, we manipulated trophic-level numbers in mesocosms using native species and confirmed that these oysters indirectly benefit from density- and trait-mediated cascades when native species occupy the top and intermediate trophic levels.

Third, by sequentially allowing the intermediate and then the top trophic level to be invaded in the mesocosms, we found that the invasive species do not produce densityor trait-mediated trophic cascades.

Fourth, we paired each crab and whelk species in the mesocosms and quantified whelk behavior and the numbers of whelks consumed by crabs. In contrast to native whelks, invasive whelks did not hide from crabs, indicating that invasive whelks are unlikely to contribute to a trait-mediated cascade. Compared to native crabs, invasive crabs were inefficient predators of whelks, indicating that invasive crabs are unlikely to contribute to a density-mediated cascade. 

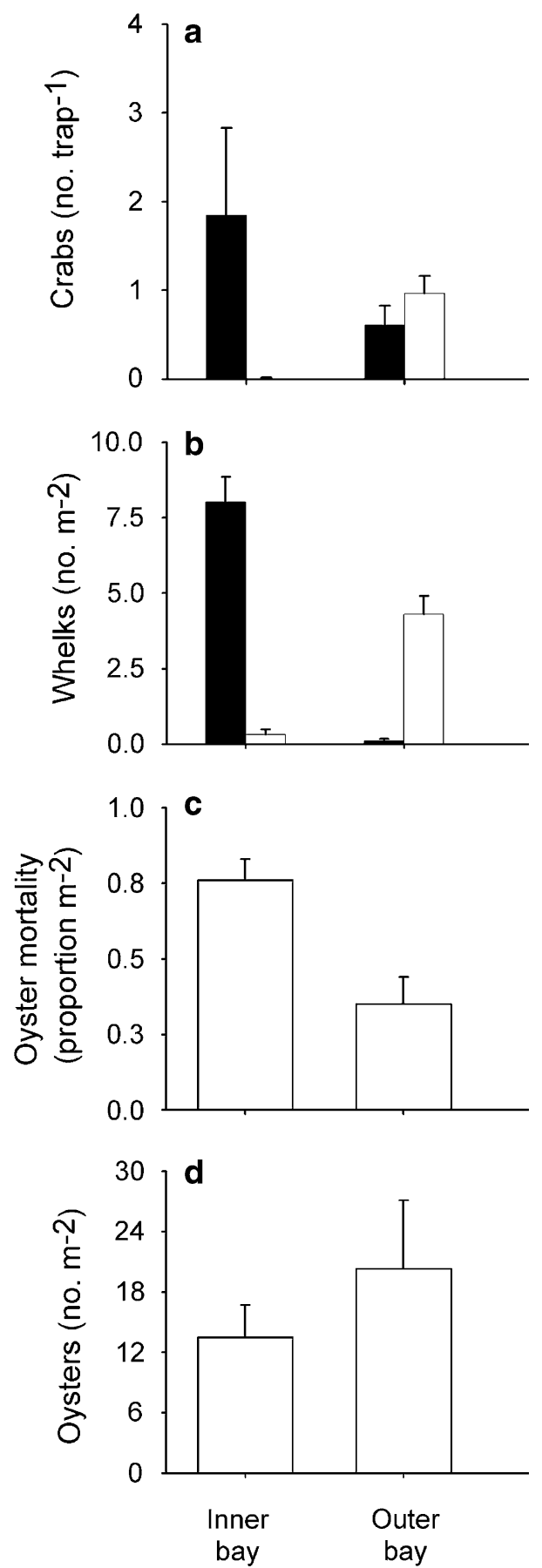

Fig. 1 Abundance (mean \pm SE) of: a invasive and native crabs, $\mathbf{b}$ invasive and native whelks, $\mathbf{c}$ native oyster mortality, and $\mathbf{d}$ native oyster density for the inner and middle regions of Tomales Bay, California, USA during April 2003-May 2006. Invaders are in closed bars, and natives are in open bars

Finally, we infer that the occurrence of at least some trophic cascades may be disrupted when invasions result in the mismatching of predator and prey traits. Because oysters filter estuarine waters (Jackson et al. 2001) and provide critical habitat that supports diverse benthic communities (Grabowski et al. 2005; Kimbro and Grosholz 2006), the failure of this estuary's invasive species to participate in established trophic cascades is having ecosystem-wide consequences.

\section{Methods}

Study system and natural histories of predator-prey

We examined how invasive species affect trophic cascades involving a three-level food chain in Tomales Bay, California $\left(38^{\circ} 07^{\prime} 17.68^{\prime \prime} \mathrm{N}, 122^{\circ} 52^{\prime} 02.86^{\prime \prime} \mathrm{W}\right.$; S1). In the middle portion of this estuary (oyster size $\pm \mathrm{SD}=48.0 \mathrm{~mm} \pm 8.6$ ), the top predator of the three-level food chain is the native rock crab (Cancer antennarius, $86.7 \mathrm{~mm} \pm 25.6$; Fig. 1a). But because the native crab does not tolerate the lower and more variable salinities of the inner portion of the bay (Gross 1957), the only top predator in the inner bay (oyster size $\pm \mathrm{SD}=35.5 \mathrm{~mm} \pm 8.8)$ is the European green crab (Carcinus maenas, $58.4 \mathrm{~mm} \pm 12.1$ ), which likely invaded in the mid- to late 1990s (Grosholz and Ruiz 1996). Although both crabs actively track prey via water-borne chemical cues (Boulding and Hay 1984; Kaiser et al. 1993), they have different feeding strategies and diets that in turn may allow one crab to more efficiently consume adult-sized whelks (Behrens Yamada and Boulding 1998; Grosholz and Ruiz 1996). For example, from previous observations, we suspect that native rock crabs (Cancridae) of all sizes are specialist predators because they can crush small gastropod prey as well as 'peel' open large gastropod prey such as the adult whelks in this study (Behrens Yamada and Boulding 1998). In contrast, we suspect the invasive green crab (Portunidae) is a generalist/omnivorous predator that consumes algae, annelids, and mollusks (Grosholz and Ruiz 1996). By overwhelmingly preferring to crush rather than peel open their prey, the relatively smaller invasive crab may be an inefficient predator of adult-sized whelks (i.e., >20.0 mm; Cunningham and Hughes 1984; Hughes and Elner 1979). Thus, the different predatory traits of the crabs may lead to density-mediated cascades and stronger reductions of whelk populations in portions of the estuary where native crabs are the top predator.

Similar to the estuary's top predators, its intermediate consumers comprise spatially segregated native and invasive whelks (Fig. 1b). While the size and diet (barnacles and oysters) of these whelks are similar, their historical experiences with predators may have lead to different antipredator strategies so that only one species behaviorally avoids crab predators. On the coastline and outer reaches of estuaries along the northeast Pacific, native whelk (Acanthinucella spirata) populations possess sufficient anti-predator 
defenses to have co-existed with specialist crab predators (Garth and Abbott 1980; Hellberg et al. 2001). But the Atlantic oyster drill (Urosalpinx cinerea) that invaded Tomales Bay in the early twentieth century originated from a northwest Atlantic estuary (Long Island Sound, USA; J. Carlton, personal communication). In this source population of invasive whelks, the anti-predator traits of avoiding crabs may be less prevalent because of the following: this region's cancrid crabs of adult sizes (i.e., Cancer irroratus $>40-50 \mathrm{~mm}$ carapace width) occur subtidally and offshore (Kraemer et al. 2007; Williams 1984), this region's European green crabs are inefficient predators of adult-sized whelks (Hughes and Elner 1979), and efficient predation by blue crabs (Callinectes sapidus) is functionally restricted to central and southern estuaries of the Atlantic coast (deRivera et al. 2005). If the native whelk's antipredator traits consist of recognizing and avoiding crab cues, then Tomales Bay's segregation of intermediate consumers may cause trait-mediated cascades to occur in some areas (those with native whelks, $22.98 \mathrm{~mm} \pm 4.7$ ) but not in others (those with invasive whelks, $23.79 \mathrm{~mm} \pm 2.9$ ).

\section{Direct causes of oyster mortality}

Because the invasive whelk is a strong consumer of oysters in its native and invaded ranges and because it only occurs in the inner bay, we suspected that invasive whelks directly caused the inner bay's high oyster mortality. But if the Olympia oyster does not tolerate warm temperatures (Brown et al. 2004) and if the inner bay's later onset of morning low tides in the summer $(\sim 30-45$ min later relative to middle bay) exposes its oysters to more stressful temperatures, then thermal stress could also explain the oyster mortality pattern. Consequently, we used a factorialfield experiment to manipulate consumers and thermal stress at one inner bay site (S1, open circle) and one middle bay site (S1, open circle). At each site, we randomly assigned 45 rocks with eight living oysters to one of five treatments: invasive-whelk enclosure, consumer exclosure, cage control, shade, and an unmanipulated control $(n=9)$. All cages were constructed using cylindrical galvanized metal frames that had $5 \times 5 \mathrm{~cm}$ frame openings and a volume of $28,274 \mathrm{~cm}^{3}$. Except for the control and shade, all cages were wrapped in clear plastic mesh (mesh openings $=0.7 \times 0.7 \mathrm{~cm}$ ). Treatment bottoms were left open, and frames were held flush to the ground by cabletying them to rebar poles staked into the ground. To quantify how invasive whelks affect oyster mortality, whelk enclosures received two adult invasive whelks (i.e., mean ambient density/unit area). To create the cage control, two openings $(15 \times 15 \mathrm{~cm})$ were cut out of a cage's opposing sides. For shade treatments, we reduced the thermal stress that oysters experience during low tides by covering the frame tops of cages with large black mesh lids $(56 \times 56 \mathrm{~cm}$ with $0.5 \times 0.5 \mathrm{~cm}$ plastic mesh openings).

Every 10 days, we counted oyster mortality as well as whelk density inside each treatment and depending on the treatment removed (exclosure) or restocked (enclosure) whelks. Oyster mortality was scored by the presence of gaping valves and/or whelk drill holes that when pressed exuded liquid and therefore indicated complete penetration of oyster shell by a whelk. After 10 weeks (May-July 2006), we used a two-way univariate analysis of variance (ANOVA) and Tukey's post hoc test to separately compare oyster mortality (proportional mean) and invasive whelk density (mean for each sampling event) using treatment and site as fixed factors. We also used multiple linear regression (MLR) and partial regression plots to assess how well oyster mortality was predicted by the density (log transformed) of each whelk species. For the partial regression involving invasive whelks, the residuals for the $y$-axis were obtained by plotting oyster mortality (dependent variable) versus the density of native whelks (independent variable) and the residuals for the $x$-axis were obtained by plotting the density of invasive whelks (dependent variable) versus the density of native whelks (independent variable). Thus, this partial regression illustrates the variation of oyster mortality explained by invasive whelk density after accounting for the variation due to native whelk density (Quinn and Keough 2002). These steps were then repeated to generate a partial regression plot for native whelks.

Because the predator-exclosure treatment in the previous experiment failed to exclude all invasive whelks at the inner-bay site (see "Results"), we were unable to eliminate thermal stress and affirm invasive whelks as causal factors of the inner-bay's oyster mortality. Consequently, we conducted an orthogonal factorial experiment only at the innerbay site that comprised invasive whelks (with and without) and shades (with and without) as factors. At the inner-bay site, we randomly assigned $36 \mathrm{PVC}$ tiles $(10 \times 10 \mathrm{~cm})$ that contained adult oysters of the same age class to one of four treatments: whelk exclosure without shade, whelk exclosure with shade, whelk enclosure without shade, and whelk enclosure with shade $(n=9)$. All cages were constructed using cylindrical galvanized metal frames that had $5 \times 5 \mathrm{~cm}$ frame openings and a volume of $6,635 \mathrm{~cm}^{3}$. We then wrapped each cage in clear plastic mesh, but used material with smaller mesh openings $(0.3 \times 0.3 \mathrm{~cm})$ to better control the presence and absence of invasive whelks. We also improved our control of invasive whelk densities by wrapping all treatment bottoms in the clear mesh. To quantify how invasive whelks affect oyster mortality, whelk enclosures received five adult invasive whelks, which is well within the range of observed densities. For shade treatments, we reduced the thermal stress that oysters experience during low tide by wrapping the entire cage in black 
Table 1 (a) From samples taken at 4-week intervals during the summer (May-August) and winter (November-February) months from 1987-1995 and then 2004-2007, seasonal averages ( \pm SE) of maximum, mean, and minimum water salinity $(P S U)$ and temperature $\left({ }^{\circ} \mathrm{C}\right)$ are presented for a middle bay and inner bay site. The $1987-$ 1995 data were obtained from a Biogeochemical Reactions In Estu- aries study conducted by Smith et al. (1989) and Largier et al. (1997) (http://lmer.marsci.uga.edu/tomales/). (b) From samples taken every 10 min between July-August of 2005 (summer) and November 2005February 2006 (winter), seasonal averages $( \pm$ SE) of maximum, mean, and minimum water salinity $(P S U)$ and temperature $\left({ }^{\circ} \mathrm{C}\right)$ are presented for a middle bay and inner bay site

\begin{tabular}{|c|c|c|c|c|c|c|c|}
\hline Data type & Season & Response variable & Middle bay & Inner bay & $t$ ratio & $P$ value & Spatial gradient \\
\hline \multirow[t]{12}{*}{$1 \mathrm{a}$} & Summer & Max PSU & $34.15 \pm 0.16$ & $34.52 \pm 0.16$ & $F_{1,22}=2.73$ & 0.11 & $=$ \\
\hline & Summer & Mean PSU & $33.38 \pm 0.22$ & $33.12 \pm 0.22$ & $F_{2,80}=0.63$ & 0.43 & $=$ \\
\hline & Summer & Min PSU & $32.28 \pm 0.44$ & $31.09 \pm 0.44$ & $F_{1,22}=3.70$ & 0.07 & $=$ \\
\hline & Summer & Max temp & $19.35 \pm 0.41$ & $20.53 \pm 0.41$ & $F_{2,22}=4.11$ & 0.05 & $<$ \\
\hline & Summer & Mean temp & $18.15 \pm 0.29$ & $19.11 \pm 0.29$ & $F_{1,74}=5.19$ & 0.03 & $<$ \\
\hline & Summer & Min temp & $16.84 \pm 0.50$ & $17.13 \pm 0.50$ & $F_{1,22}=0.17$ & 0.68 & $=$ \\
\hline & Winter & Max PSU & $32.5 \pm 0.59$ & $32.26 \pm 0.59$ & $F_{1,22}=0.08$ & 0.78 & $=$ \\
\hline & Winter & Mean PSU & $30.48 \pm 0.81$ & $29.0 \pm 0.79$ & $F_{1,61}=1.70$ & 0.20 & $=$ \\
\hline & Winter & Min PSU & $28.38 \pm 1.63$ & $25.91 \pm 1.63$ & $F_{1,22}=1.61$ & 0.29 & $=$ \\
\hline & Winter & Max temp & $13.83 \pm 0.60$ & $14.11 \pm 0.60$ & $F_{1,22}=0.11$ & 0.74 & $=$ \\
\hline & Winter & Mean temp & $11.64 \pm 0.46$ & $11.77 \pm 0.45$ & $F_{1,61}=0.04$ & 0.84 & $=$ \\
\hline & Winter & Min temp & $9.80 \pm 0.52$ & $9.79 \pm 0.52$ & $F_{1,22}=0.0$ & 0.99 & $=$ \\
\hline \multirow[t]{12}{*}{$1 b$} & Summer & Max PSU & $32.40 \pm 0.22$ & $31.77 \pm 0.22$ & $F_{1,122}=4.10$ & $<0.05$ & $>$ \\
\hline & Summer & Mean PSU & $27.99 \pm 0.29$ & $29.62 \pm 0.29$ & $F_{1,122}=17.09$ & $<0.0001$ & $<$ \\
\hline & Summer & Min PSU & $20.60 \pm 0.45$ & $24.69 \pm 0.45$ & $F_{1,122}=41.86$ & $<0.0001$ & $<$ \\
\hline & Summer & Max temp & $20.10 \pm 0.15$ & $21.05 \pm 0.15$ & $F_{1,122}=20.28$ & $<0.0001$ & $<$ \\
\hline & Summer & Mean temp & $19.16 \pm 0.12$ & $20.24 \pm 0.12$ & $F_{1,122}=38.34$ & $<0.0001$ & $<$ \\
\hline & Summer & Min temp & $17.81 \pm 0.12$ & $19.42 \pm 0.12$ & $F_{1,122}=89.86$ & $<0.0001$ & $<$ \\
\hline & Winter & Max PSU & $27.25 \pm 0.33$ & $24.18 \pm 0.33$ & $F_{1,238}=43.52$ & $<0.0001$ & $>$ \\
\hline & Winter & Mean PSU & $25.58 \pm 0.51$ & $21.7 \pm 0.51$ & $F_{1,238}=28.82$ & $<0.001$ & $>$ \\
\hline & Winter & Min PSU & $22.06 \pm 0.81$ & $17.97 \pm 0.81$ & $F_{1,238}=12.67$ & $<0.001$ & $>$ \\
\hline & Winter & Max temp & $12.78 \pm 0.12$ & $13.17 \pm 0.12$ & $F_{1,238}=5.51$ & $<0.05$ & $<$ \\
\hline & Winter & Mean temp & $12.28 \pm 0.12$ & $12.54 \pm 0.12$ & $F_{1,238}=2.32$ & 0.13 & $=$ \\
\hline & Winter & Min temp & $11.82 \pm 0.13$ & $11.89 \pm 0.13$ & $F_{1,238}=0.16$ & 0.70 & $=$ \\
\hline
\end{tabular}

Statistical results ( $t$ ratio and $P$ value) are also presented for each seasonal comparison between sites. The orientation of a significant spatial gradient is also presented as ">" (middle bay greater than inner bay), "=" (no significant spatial gradient), and " $<$ " (middle bay is less than inner bay)

mesh (with $0.5 \times 0.5 \mathrm{~cm}$ plastic mesh openings). Except for a 6 -week rather than a 10-week duration (May-July 2008), all other methods of this second experiment resembled that of the first experiment.

In addition to temperature, stressful salinity levels may also explain why oyster mortality is higher in the inner bay. During intense winter storms, we have observed that fresh-water input into the head of the estuary can reduce the salinity of surface water more in the inner bay than in the middle bay. To test whether oyster mortality of the inner bay exceeds that of the middle bay during winter storms, we outplanted oysters of the same age class at an east-west pair of middle-bay (closed and open circles, S1) and inner-bay sites (closed and open circles, S1). Before beginning this experiment, these oysters were obtained by spawning adult oysters under controlled conditions in the Bodega Marine Laboratory (BML). Larval oysters were then settled onto PVC tiles $(10 \times 10 \mathrm{~cm})$ and eight tiles were deployed to each of the four sites in the late autumn of 2005 as part of a separate study. Here, we present mean oyster mortality from the middle- and inner-bay sites over a 2-month period (November 2005January 2006). This time period coincided with a winter storm in central California that produced $39.1 \mathrm{~cm}$ of rain at BML (http://www.bml2.ucdavis.edu/boon/raindatasets. html) and helped make the 2005-2006 rainy season the wettest since 1997-1998. During this experiment, winter storms reduced average salinity values in the inner bay (22.44) more than in the middle bay (26.88, see Table 1$)$. Before comparing mortality means with a $t$ test, we used a power transformation (1.5) to satisfy parametric assumptions.

\section{Indirect causes of oyster mortality}

To test whether the absence of trophic cascades further explains the high oyster mortality in the inner bay (Fig. 1c), 
we used mesocosms to assemble three food webs that represented different areas within the estuary. We then conducted a manipulative experiment with each food web. For all cases, native oysters were the basal species. In one food web (representing the middle bay), both the top predator and the intermediate consumer were native. In a second food web (transition between middle and inner bay), the top predator was native and the intermediate consumer was invasive. In a third food web (inner bay), both the top predator and intermediate consumer were invasive. Crab-size differences among food webs were minimized by using only adult-sized green crabs $(73.87 \pm 1.66 \mathrm{~mm})$ and native crab sizes approximating the observed mean $(95.11 \pm$ $1.94 \mathrm{~mm})$. For each food-web experiment, we assigned flow-through mesocosms (1.0 m diameter) at BML to one of four treatments: (1) oysters only (basal species control); (2) oysters and whelks (no trophic cascade possible); (3) oysters, whelks, and one non-lethal crab with restricted claws (trait-mediated cascade possible); (4) oysters, whelks, and one lethal crab with unrestricted claws (density- and trait-mediated cascades possible). While lethal crabs could consume whelks, we prevented non-lethal crabs from consuming whelks by wrapping mesh gloves around their claws. Each mesocosm received three gallons of sand and five rocks $(\sim 15 \times 15 \mathrm{~cm})$ with $3-5$ living oysters per rock. All treatments except the basal species control also received 20 whelks, which represents natural whelk densities. Because whelk behavior affected their susceptibility to predation (i.e., some whelks hid under rocks and climbed up tank walls), every day and evening we quantified the number and location of visible whelks as well as number of whelks consumed by crabs. For visible whelks, we noted whether whelks appeared to be consuming oysters or avoiding crabs by climbing up mesocosm walls. After 6 days, we ended the experiment and quantified oyster mortality. Using the mean of the observational data for days 1-6, we estimated how non-lethal and lethal crabs affected whelk avoidance behavior (number of whelks not visible + high on tank walls) and per capita oyster consumption.

To increase replication, we repeated these experiments in time. Before combining data from separate trials, we used an ANOVA to analyze whether differences among treatment means varied across time. Because we did not find any treatment $\times$ time interactions, we combined data for each food web experiment and used ANOVA to test whether response means differed among treatments. For each food web, four responses were analyzed: the mean number of whelks that avoided crabs, the number of whelks consumed by crabs, and the total and per capita number of oysters consumed by whelks. When analyzing the data on whelk avoidance behavior, we used the mean number of whelks consumed by crabs as a covariate in an analysis of covariance (ANCOVA). Because the number of hiding whelks likely depended on the number of living whelks, this analysis allowed us to correct for the lower whelk densities observed in the lethal-crab treatment. Although the lack of predation in the oysters-whelks and oysterswhelks-non-lethal crab treatments prevented the covariate slopes among all three treatments from being homogenous, we proceeded with the ANCOVA because the covariate is an important biological effect of interest (Quinn and Keough 2002). Data failing to meet parametric assumptions were either $\log$ transformed or analyzed with a non-parametric Wilcoxon/Kruskal-Wallis test.

To assess whether physical conditions-rather than native crabs-spatially segregate the native and invasive intermediate consumers, we examined two different types of data concerning the water conditions at a middle and inner bay site (S1, open circles). First, at 4-week intervals during the summer (May-August) and winter (NovemberFebruary) months from 2004-2007, we quantified salinity, temperature, and depth with a boat-based CTD profiler (SeaBird Electronics) $100-200 \mathrm{~m}$ offshore of each site. Each site's depth profile was vertically averaged to obtain temperature and salinity means. We then increased the temporal scope of these data by incorporating analogous monthly data from a long-term study conducted between 1987-1995 (Largier et al. 1997; Smith et al. 1989). These monthly data were averaged to produce seasonal means of temperature and salinity for each site. Within each individual season (e.g., summer 2006), we used the replicate months (e.g., May-August) to obtain seasonal maximum and minimum values for each site, and these individual season data were averaged to produce seasonal maximum and minimum means for each site. Second, to examine site differences at a higher temporal resolution, we deployed data loggers (1 sample/10 $\mathrm{min}$ ) at each site from JulyAugust of 2005 and November 2005-February 2006. Seasonal means, maximums, and minimums for temperature and salinity at each site were generated by averaging the daily means, maximums and minimums, respectively. For both types of data, we used a $t$ test to compare the mean, maximum, and minimum values of seasonal temperature and salinity between sites.

Interactions between each crab and each whelk

A separate laboratory experiment was conducted to explore further the matching of predator and prey traits between each species of crab and whelk. In this experiment, 15 native and invasive whelks (30 total) were placed in mesocosms similar to those described above, except sediment and rocks were not provided. Each mesocosm was then randomly assigned to one of three predator treatments $(n=10)$ : no crab, one native crab, or one invasive crab. Every day, we quantified the number and identity of whelks 
consumed by crabs, noted the crabs' foraging method (i.e., peeling versus crushing), and quantified the number of whelks that avoided crabs by climbing up tank walls. Each day, we minimized the effect of whelk avoidance behavior on crab consumption by returning whelks on tank walls to the bottom of tanks. After 6 days or when whelk density was reduced by $50 \%$, we ended the experiment and averaged the daily observational data. To protect against Type I error rate (Scheiner and Gurevitch 2000) and to determine if the avoidance behavior of both whelk species changed among predator treatments, we conducted a multivariate analysis of variance (MANOVA). Where multivariate analysis indicated a significant effect at $P \leq 0.05$, we used the number of whelks consumed as a co-variate in an ANCOVA and then Tukey's post hoc test to examine each response variable (i.e., native whelk behavior and invasive whelk behavior) (Underwood 1981). For the whelk mortality data, we also conducted a MANOVA to assess how three response variables changed across treatments: total whelk mortality (i.e., predator efficiency), invasive whelk mortality, and native whelk mortality. Where multivariate analysis indicated a significant effect at $P \leq 0.05$, we used a $t$ test to compare how each response variable differed between the native and invasive crab treatments. Statistical analyses were performed in JMP 5.1 software (SAS Institute, Cary, NC).

\section{Results}

Direct causes of oyster mortality

Our field experiment with different cage treatments indicated site by treatment interactions for oyster mortality $\left(F_{4,77}=7.95, \quad P<0.0001\right)$ and invasive whelk density $\left(F_{4,77}=8.08, P<0.0001\right)$. In the middle bay, only the presence of invasive whelks significantly increased oyster mortality relative to the control (Tukey's post hoc test, $t=3.26$, $P<0.05$; Fig. 2a). The inner bay, however, had high oyster mortality regardless of treatment. This difference between sites resulted because of differences in invasive whelk density across treatments at the two sites (Tukey's post hoc test, $t=3.26, P<0.05$; Fig. $2 \mathrm{~b}$ ): the consumer exclosures in the inner bay failed to exclude all invasive whelks, and the cage control and shades actually attracted them. In addition, this experiment coincided with the reproductive stage of invasive whelks, so that by chance the two adult whelks randomly assigned to whelk enclosures often spent more time mating than consuming oysters. Thus, invasive whelk predation was actually lower in whelk enclosures than in cage control or shade treatments and often equaled that of consumer exclosures. When the densities of each whelk species were used in a multiple linear regression, we found that invasive and native whelk densities explained $67 \%$ of
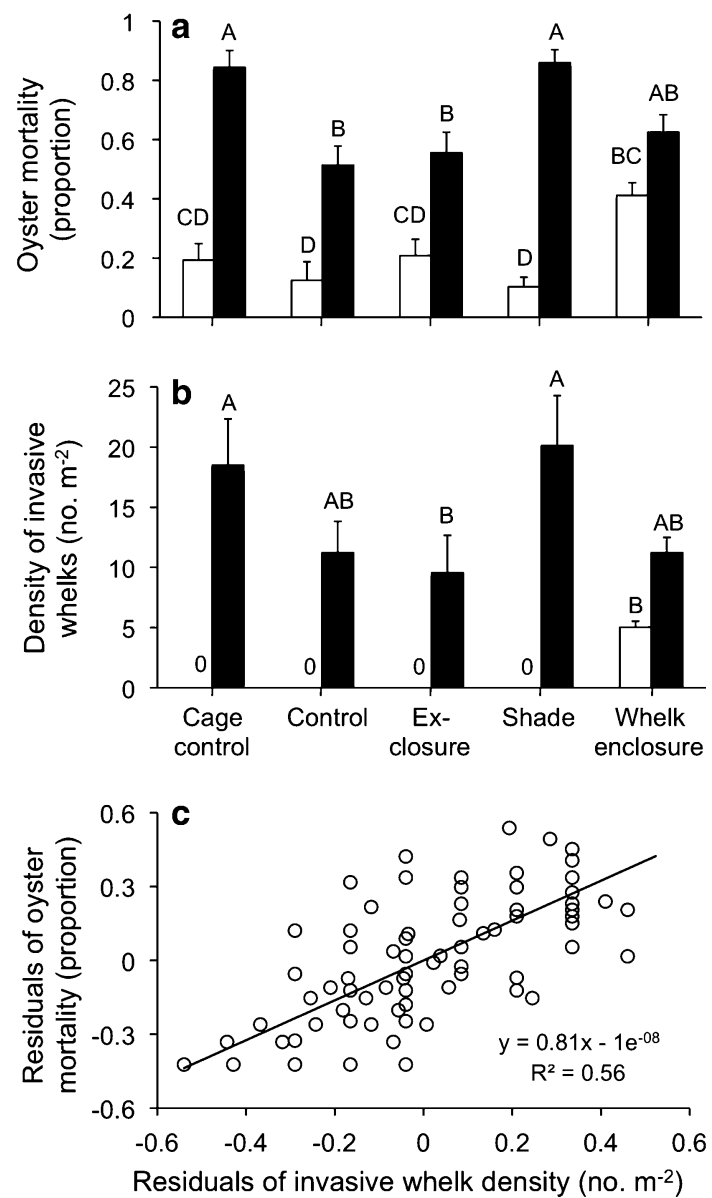

Fig. 2 Mean ( \pm SE) a oyster mortality. b Invasive whelk density during a 10-week experiment in the inner bay (closed bars) and middle bay (open bars). $\mathbf{c}$ The residuals of oyster mortality are plotted versus the residuals of invasive whelk density over the 10 -week period based on the results of a multiple linear regression

oyster mortality variance (MLR, $R^{2}=0.67, F_{2,84}=86.02$, $P<0.0001)$. While the residuals of invasive whelk densities were positively associated with the residuals of oyster mortality $\left(F_{1,85}=106.4, P<0.0001\right.$, Fig. $\left.2 \mathrm{c}\right)$, the residuals of native whelk densities were negatively and more weakly associated with the residuals of oyster mortality $\left(F_{1,85}=\right.$ $\left.6.57, P<0.05, y=-0.27 x-3.1 \mathrm{e}^{-16}, R^{2}=0.07\right)$.

In our second field experiment at the inner-bay site, the enclosure/exclosure treatments effectively included and excluded whelks. In addition, oyster mortality was not interactively influenced by whelk presence and shading or by the main effect of shading (overall ANOVA, $F_{3,34}=$ 19.48, $P<0.0001$; whelk $\times$ shade $F_{1,34}=0.43, P=0.51$; shade $\left.F_{1,34}=1.96, P=0.17\right)$. The main effect of invasive whelks, however, significantly increased oyster mortality $\left(F_{1,34}=54.8, P<0.0001\right.$, Fig. 3a).

Similar to the insignificant effect of shading and thus thermal stress, the results of our winter experiment suggest that lowered salinities cannot directly account for the oyster mortality pattern: a winter rainfall event of $39.1 \mathrm{~cm}$ (15.4 in.) 


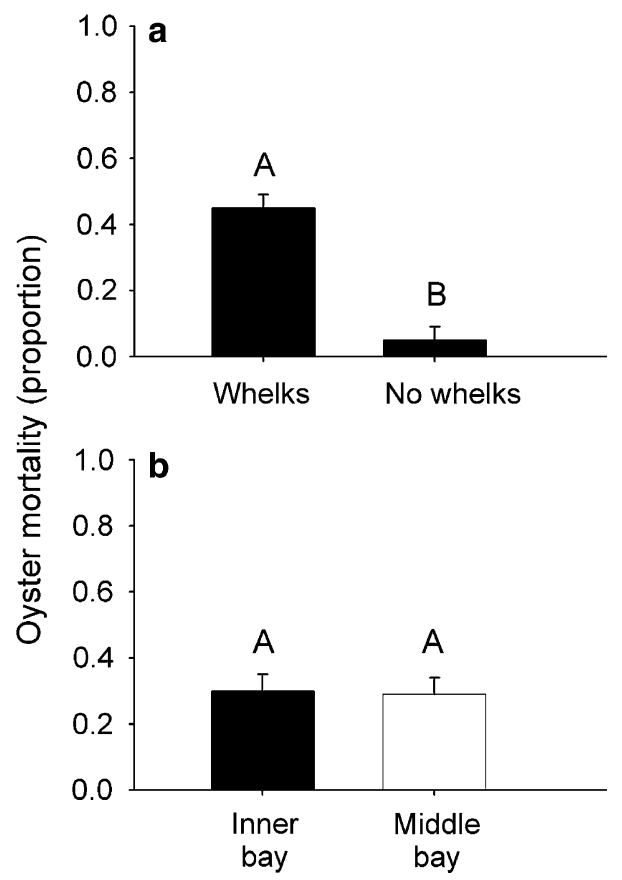

Fig. 3 a Oyster mortality (mean \pm SE) at an inner bay site during a 6-week experiment in summer 2008 in which whelk presence was the only significant factor. b Oyster mortality (mean \pm SE) in the inner bay (closed bars) and middle bay (open bars) during 2 months of high rainfall, November 2005-January 2006. Statistically different means based on post hoc tests $(P<0.05)$ are indicated with different letters

that created average salinities of 22.44 in the inner bay and 26.88 failed to spatially vary oyster mortality $(t$ ratio $=$ $-0.05, P=0.96$; Fig. 3b).

\section{Indirect causes of oyster mortality}

In our mesocosm experiments, whelks consistently consumed oysters (total and per capita) in the no trophic-cascade treatments (Fig. 4g-l; see S6 for all mesocosm statistics). The presence of trophic cascades and reduced oyster mortality, however, depended on whether a food web had native versus invasive crabs and whelks. With native crabs and native whelks, oysters benefited from equally strong density- and trait-mediated cascades (Fig. 4g, j), because lethal crabs consumed whelks (Fig. 4d) and non-lethal crabs caused whelks to hide rather than eat oysters (Fig. 4a). But a trait-mediated cascade based solely on whelks recognizing crabs disappeared when native whelks were replaced with invasive whelks (Fig. 4b, e, h, $\mathrm{k}$ ), which continued to consume oysters in the presence of non-lethal native crabs. As a result, lower oyster mortality in this food web depended mostly on a strong densitymediated cascade. When native crabs and native whelks were replaced with invasive species (Fig. $4 \mathrm{c}, \mathrm{f}, \mathrm{i}, \mathrm{l}$ ), the trait-mediated cascade based solely on recognition was eliminated and the density-mediated cascade was signifi- cantly weakened: non-lethal invasive crabs did not alter whelk foraging behavior, and lethal invasive crabs failed to consume enough whelks to reduce both the total $(F=3.47$, $P=0.06)$ and per-capita number $(F=0.96, P=0.41)$ of oysters consumed.

While the presence of food-web interactions may differ between the middle and inner bay, our monitoring results failed to find dramatic abiotic differences between the inner and middle bay that can explain the distribution of invasive whelks. During the summer (May-August) and winter (November-February) months from 1987-1995 and 20042007 , the mean $\left(19.11^{\circ} \mathrm{C}\right)$ and maximum $\left(20.53^{\circ} \mathrm{C}\right)$ water temperature of the inner bay was statistically warmer than the middle bay by $1^{\circ}$ (Table 1a). But the temperature threshold at which invasive whelks stop feeding is $7.5^{\circ} \mathrm{C}$ and they can survive $5^{\circ} \mathrm{C}$ water for several months (Hanks 1957). While more differences between sites were detected with the higher resolution monitoring data (Table 1b), these site differences also do not account for the absence of invasive whelks from the middle bay. In fact, average winter salinity of the inner bay was significantly lower than the middle bay and approached a lethal threshold for invasive whelks (1517; Federighi 1931), suggesting that invasive whelks may be located in a sub-optimal portion of the bay.

Interactions between each crab and each whelk

In our separate experiment that further explored the matching of predator and prey traits between each species of crab and whelk, the grouped behavioral response of the two whelk species changed across the predator treatments (MANOVA Wilk's Lambda $F_{4,48}=3.90, \quad P=0.01$; Fig. 5a). In comparison to the no-crab treatment, native whelks significantly avoided both native and invasive crabs (ANCOVA $F_{3,24}=3.06, P=0.05$, number whelks consumed, $F=6.01, P=0.02$; treatment, $F=4.29, P=0.03$; Tukey's test $=2.50$ ). In contrast, invasive whelks avoided neither crab (ANCOVA $F_{3,24}=3.28$. $P=0.18$; number whelks consumed, $F=0.87, P=0.36$; treatment, $F=1.18$, $P=0.32$ ). Because whelk behavioral responses were minimized, both crab species consumed more whelks in this than in the previous experiment. But by peeling open and crushing their prey, native crabs still consumed more than twice as many whelks as did invasive crabs (MANOVA Wilk's Lambda $F_{6,46}=7.18, P=0.0001 ; t$ test $=3.06$, $P=0.005$; Fig. 5b); invasive crabs tried consuming whelks only by crushing the apexes of their shell. While native crabs consumed more invasive whelks than did invasive crabs ( $t$ test $=4.20, P=0.001)$, the size of each crab did not significantly correlate with the number of whelks consumed (native $\mathrm{crab}=0.003 \mathrm{x}+10.20, R^{2}=0.00003, P=0.99$; invasive crab $=0.33 x-19.41, R^{2}=0.28, P=0.12$ ). Despite its statistical insignificance, a positive relationship between 
Middle bay native crabs and native whelks
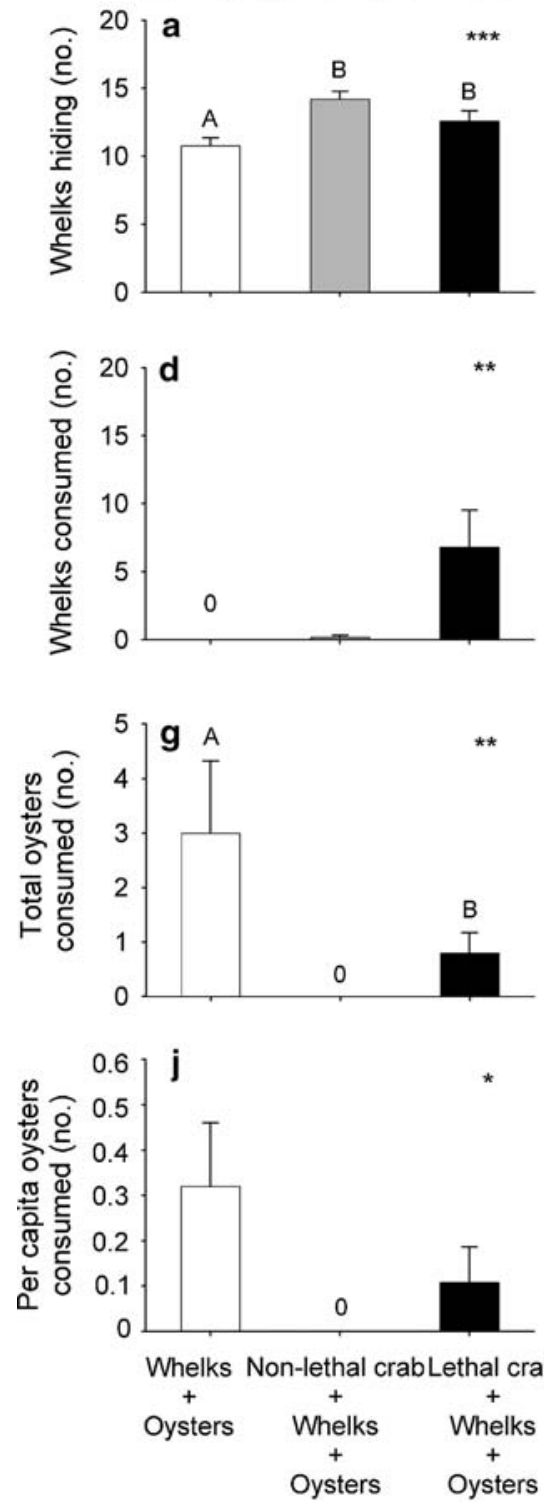

Middle-inner bay transition native crabs and invasive whelks
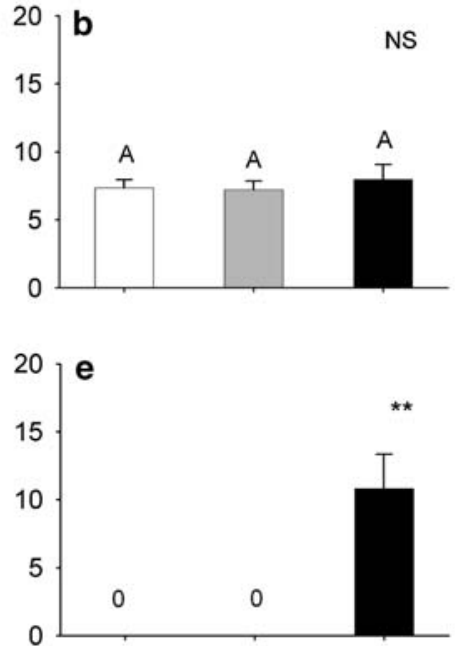

Inner bay

invasive crabs and invasive whelks
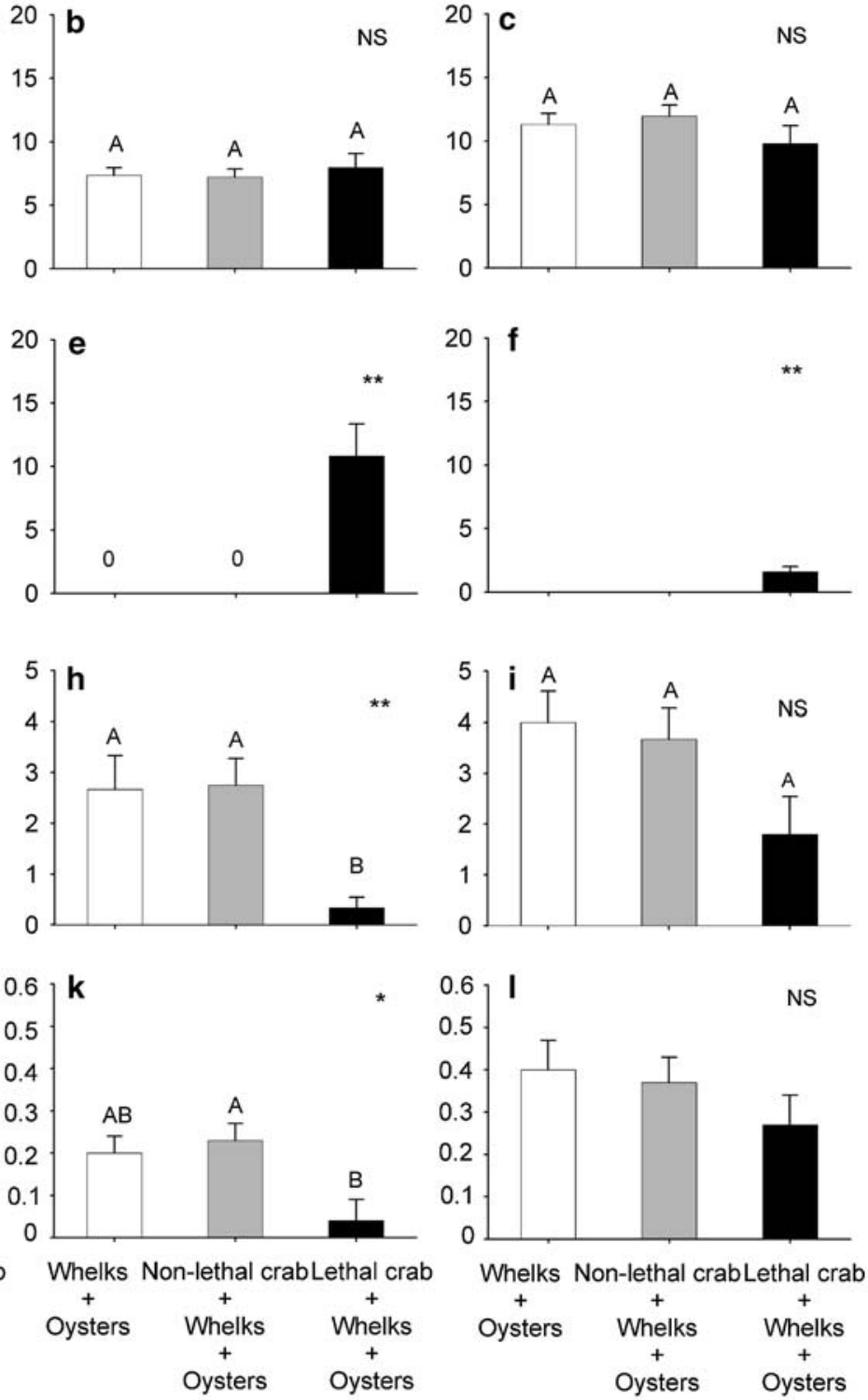

Trophic cascade treatment

Fig. 4 Responses by three trophic cascade treatments (whelks and oysters; non-lethal crab, whelks, and oysters; lethal crab, whelks, and oysters) to food web experiment simulating species mix at the middle bay (left column) with native crab top predator and native whelk intermediate predator, the middle-inner bay transition (middle column) with native crabs and invasive whelks, and the inner bay (right column) with invasive crabs and invasive whelks. Response variables shown

crab size and number of whelks consumed appears more important for invasive than native crabs.

\section{Discussion}

Our results show that invasive species can reorganize an estuary's food web by altering trophic cascades. We found are, $\mathbf{a}-\mathbf{c}$ number of whelks hiding, $\mathbf{d}-\mathbf{f}$ number of whelks consumed, $\mathbf{g}-\mathbf{i}$ total number of oysters consumed, and $\mathbf{j}-\mathbf{l}$ per-capita oyster consumption. Non-lethal crabs are those with mesh claw coverings. Significance levels are indicated by asterisks $(* P<0.05, * * P<0.01$, $* * * P<0.001, N S$ not significant). Letters above error bars indicate statistically significant differences using Tukey's post hoc test (except in $\mathbf{g}$ where $t$ test was used)

that the middle region of Tomales Bay has less oyster mortality and more biologically diverse oyster habitat than does the inner bay (Fig. 1c, d). Despite historically receiving less recruitment (Kimbro, unpublished data), the middle bay has less oyster mortality and more living oysters not because the region is physically less stressful for oysters, but because this region lacks invasive whelks (Figs. 1, 2, 3). According to our survey (Fig. 1) and mesocosm experiments 

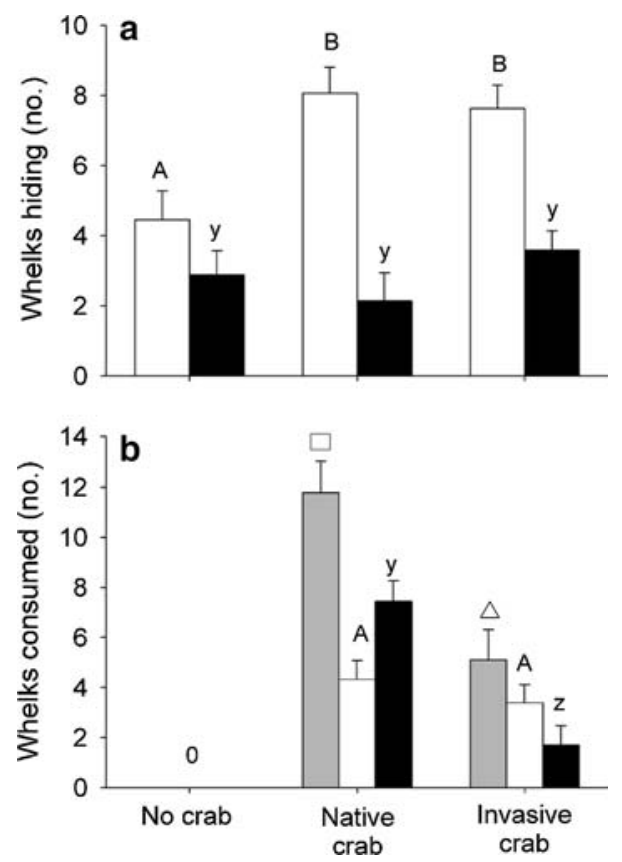

Fig. 5 a Least-squares mean number of whelks hiding. b Crab consumption of whelks under three treatments: no crab, native crab, and invasive crab. Results of Tukey post hoc tests among the three treatments are shown for native whelks (open bars), invasive whelks (closed bars), and total whelks (gray bars). Different letters and symbols above each group of whelks indicate statistically significant differences $(P<0.05$, uppercase letters for native whelks, lowercase letters for invasive whelks, and symbols for total whelks)

(Fig. 4d, g, j), oysters are also indirectly maintained in this region by trophic cascades involving native crabs and native whelks. Supporting this interpretation, we have found whelk shells with distinctive native crab predation marks in the low intertidal zone $(<-1.0 \mathrm{~m})$ of middle-bay sites that could be the result of a density-mediated cascade generated by native crabs. In addition, at sites with fewer native crabs, native whelks were equally distributed in the upper and lower intertidal areas of the oyster zone. But at middle-bay sites with more native crabs, twice as many native whelks were found in the upper than in the lower intertidal oyster zone (Kimbro, unpublished data). Furthermore, during our first field experiment, the density of native whelks in the low intertidal zone of a middle bay site with native crabs was not positively associated with oyster mortality. These observations could be the result of a trait-mediated cascade whereby native whelks hide rather than forage in the presence of crabs or relocate higher intertidally to avoid crabs and to consume barnacles instead of oysters. Similar reductions in foraging activity and behavioral shifts in habitat use are commonly displayed by prey in other systems (Gastreich 1999; Power et al. 1985). In contrast, our survey and experimental results (Figs. 1, 2, 3, 4) indicate that the failure of invasive whelks and invasive crabs to generate strong trait- and density-mediated cascades is allowing invasive whelks to deplete oysters in the inner bay.

Because the distinct, non-overlapping distribution of invasive and native species throughout the estuary explains why oyster mortality and abundance varies, it is interesting to consider why these species remain separated. From distribution patterns throughout their range (Garth and Abbott 1980; Hellberg et al. 2001) and from our unpublished data showing that native whelks become unresponsive at reduced salinity levels sooner than do invasive whelks, we assume that native whelks are excluded from the inner bay because they do not tolerate the lower salinity extremes that often occur in the upper estuary during large winter storms (Table 1). Because we have observed high mortality of native crabs and zero mortality of invasive crabs when exposed to low salinities, low winter salinities also explain the native crab's distribution (Gross 1957). Site differences in water salinity or temperature, however, do not adequately explain why invasive whelks and crabs are absent from the less physically stressful middle bay (Federighi 1931; Hanks 1957). Alternatively, the absence of a traitmediated cascade could prevent invasive whelks from locally co-existing with native crabs in the middle bay. In our laboratory experiments, invasive whelks did not behaviorally respond to native crabs before being consumed (Figs. 4b, e, h, k and 5a, b). Consistent with the biotic resistance and increased susceptibility hypotheses (Colautti et al. 2004; Darwin 1859; Elton 1958), the invasive whelk's naivete to native crabs and the ensuing density-mediated cascade likely increase the middle bay's biotic resistance, which can explain why invasive whelks and high oyster mortality do not occur beyond the inner bay. Similarly, native crabs consuming invasive crabs explains why invasive crabs are restricted to the inner bay (McDonald et al. 1998).

While spatial variation in trophic cascades indirectly controls the oyster mortality pattern, we hypothesize that these trophic cascades may ultimately depend on the historical exposure of each crab and whelk species. Within the context of trait-mediated cascades, an intermediate consumer's historical exposure to an efficient top predator could have selected for individuals that avoid and escape predation by recognizing alarming cues (Sih 1985; Strauss et al. 2008; Vermeij 1982b). And for density-mediated cascades, it is reasonable that the top predator's evolutionary history with common prey (and its own predators) selected a dietary preference, hunting mode, and/or morphological features that facilitate hunting and efficiently consuming a widely available intermediate consumer (Vermeij 1982b). Although the behavior underlying trophic cascades could be learned by individual top predators and intermediate consumers, each animal's capacity for learning would be influenced by the presence/absence of innate morphological 
or behavioral traits that would increase fitness and ultimately be selected for within a population over time (Berger et al. 2001; Cox and Lima 2006; Smith 2004). We therefore suspect that a common feature of functioning cascades is that the top predator and intermediate consumer species share an evolutionary history and/or have historical exposure with similar types of predator and prey species so that their predator and anti-predator strategies are well matched.

Although our results could be due solely to the speciesspecific traits of the organisms in this study, three lines of evidence suggest historical exposure is important. First, not only do native whelks recognize and respond to the presence of non-lethal native crabs, but they also display a behavioral response to non-lethal invasive crabs (Fig. 5a). As predicted by Cox and Lima (2006), the historical exposure to native crabs can explain why a general behavioral response to smaller but functionally similar invasive crabs has also been selected for in native whelk populations (Garth and Abbott 1980; Hellberg et al. 2001). Invasive whelks, however, generally appear naive to the threat of crabs-regardless of predator size-because they did not respond to non-lethal native or invasive crabs (Fig. 5a). These results and the paucity of large, efficient crab predators in the upper reaches of northwest Atlantic estuaries (Hughes and Elner 1979, Williams 1984; deRivera et al. 2005, Kraemer et al. 2007) suggest that lower predation pressure did not select for species-specific or general behavioral responses to crabs within the source population of invasive whelks. Alternatively, the anti-predator strategy selected for in this source population of invasive whelks may be to continuously feed in order to grow quickly into a size refuge from predation. While this strategy may work sufficiently with green crabs and other predators in northwest Atlantic estuaries, it appears to be a naive and insufficient strategy for dealing with crabs native to northeast Pacific estuaries. Therefore, the historical exposure of the whelk species can explain the degree of matching between predator and prey traits in our system and thus the presence of trait-mediated cascades.

A second line of evidence supporting the importance of historical exposure is that differing foraging strategies (which must be selected for and must evolve through time) lead to differing abilities of native versus invasive crabs to consume adult whelks and to produce a density-mediated cascade in Tomales Bay. Regardless the size of the crab, our final laboratory experiment (Fig. 5b) suggests that specialist native crabs efficiently consume both native and invasive whelks by peeling open and crushing these relatively large gastropods. But even when whelk avoidance behavior was minimized, generalist invasive crabs still consumed far fewer whelks than did native crabs (Fig. 5b). Because invasive crabs consumed whelks only by crushing the shell apex, their ability to consume either whelk appears to be dictated by crab size; higher whelk consumption occurred only when crab sizes were well above observed modal size classes (Grosholz and Ruiz 1996). Although invasive crabs may efficiently consume juvenile invasive whelks, this predation has not reduced the population of invasive whelks (mean size of $23.79 \mathrm{~mm} \pm 2.94$ ) enough to prevent the oyster mortality pattern (Fig. 1). Consequently, the invasive crab's historical exposure to other prey may have selected a naive foraging strategy with regards to efficiently consuming adult sized whelks (Hughes and Elner 1979) and creating strong density-mediated cascades.

A third line of evidence supporting our historical exposure hypothesis also helps reconcile our results with other studies demonstrating that invasive species do participate in trophic cascades. In the northwest Atlantic rocky-shore system, the herbivorous snail (Littorina littorea) and European green crab (Carcinus maenas) are non-native predator-prey that interact to create both density- and trait-mediated cascades benefiting fucoid algae (Lubchenco 1978; Trussell et al. 2002). Although these top and intermediate-level organisms are invaders, they are not naive to one another because they have interacted both with each other and similar types of predator-prey in their native European range (Vermeij 1982a). We therefore do not believe that every invasive species will fail to participate in trophic cascades. Rather, an invader's effect on food-web dynamics will depend on the types of predator or prey strategies that it historically interacted with. For example, intermediate consumers historically exposed to efficient top predators that sit-and-wait before ambushing their prey may more successfully invade food webs with top predators by participating in trait-mediated cascades (Schmitz 2008).

Although the results of our study support our hypothesis and other published predictions concerning historical exposure between predator and prey (Vermeij 2001; Blackburn and Gaston 2005; Cox and Lima 2006; Strauss et al. 2008), several limitations of our study preclude us from definitively concluding that historical exposure underlies the results. First, we did not test how invasive crabs and native whelks interact to influence oysters via trophic cascades. While the final laboratory experiment (Fig. 5) suggests this food web would contain a trait-mediated cascade and a weak density-mediated cascade, we did not investigate this last food web because it seemed unrelated to the large-scale pattern of oyster mortality (Fig. 1). Second, our conclusions depended on quantifying the presence of a trait-mediated cascade based solely on whelks recognizing alarming crab cues as opposed to one based on whelks detecting cues released by conspecifics when being eaten by crabs (e.g., Trussell et al. 2002). Because top-predators may also create interactions between trait- and density-mediated cascades when they consume intermediate consumers, future 
experiments will need to address whether different types of trait-mediated cascades are more susceptible to biological invasions. Finally, an alternative explanation for our results is that the native and invasive species patterns are caused by trait variation that depends more on phylogenetic constraints than on historical exposure between predator and prey, because functionally similar native predators often possess different hunting strategies (Schmitz 2008). Additional studies are needed to determine the relative importance of phylogeny versus historical exposure.

While previous studies of trophic cascades have focused on the impacts of removing top predators via habitat loss or overharvesting, it has recently become clear that these food-web interactions also depend on a predator's identity and hunting strategy (Schmitz et al. 2004; Schmitz 2008). Adding to this relatively new focus, our work demonstrates another unforeseen consequence of human-mediated invasions (Grosholz 2002). When native top predators and intermediate consumers are replaced with invasive species, biological invasions can dramatically alter food webs by disrupting trophic cascades. All trophic levels within a food web locally co-exist only when top predators and intermediate consumers interact via both density- and trait-mediated cascades. But an invasive intermediate consumer capable of depleting an important foundation species appears to be excluded from the food web, because the invader's naivete prevents it from recognizing and successfully avoiding a native top predator before being consumed. Thus, echoing the conclusions of previous work on trophic cascades (Myers et al. 2007), biological invasions (Parker et al. 2006), and biodiversity-ecosystem function (Jackson et al. 2001; Worm et al. 2006), our results suggest that marine food webs can be conserved by protecting native top predators that simultaneously regulate the foraging of native intermediate consumers (via density- and trait-mediated cascades) and exclude invasive intermediate consumers (via density-mediated cascades). Furthermore, although native species extinctions at the local and regional scale can be balanced by invasions of functionally similar species (Sax and Gaines 2003), our results suggest that naivete can prevent top predators and/or intermediate consumers in invaded food webs from re-creating historically important trophic cascades that maintain biodiversity and ecosystem function (Schmitz 2008).

Acknowledgments We thank C. Hays, A. Hughes, K. Hultgren, B. Jaffee, E. Sanford, O. Schmitz, A. Sih, J. Stachowicz, G. Trussell, and anonymous reviewers for comments and ideas that improved this manuscript. L. Budd, A. Chang, M. Ferner, A. Hettinger, M. Nydam, M. O'Leary, and B. Steves generously provided field assistance. We also thank B. Steves for helping produce the manuscript's figures. This research was supported by grants from the University of California (UC) Marine Council/Coastal Quality Environmental Initiative (to D.L.K.), UC Davis Graduate Group in Ecology (to D.L.K.), National Park Service at Point Reyes National Seashore (to D.L.K.), National Science
Foundation Biological Invasions IGERT Program at UC Davis (NSFDGE \#0114432 to D.L.K.), National Oceanic and Atmospheric Administration (to E.D.G), National Parks Service-California Cooperative Ecosystem Studies Program (to E.D.G.), Pacific States Marine Fisheries Commission (to E.D.G.), UC Exotic/Invasive Pest and Disease Program (to E.D.G.), and National Science Foundation-Research Experience for Undergraduates (Grant DBI0453251 to N.J.N and N.M.T.). This paper is contribution number 2446, Bodega Marine Laboratory, University of California-Davis. The experiments within this manuscript comply with the laws of the United States.

Open Access This article is distributed under the terms of the Creative Commons Attribution Noncommercial License which permits any noncommercial use, distribution, and reproduction in any medium, provided the original author(s) and source are credited.

\section{References}

Abrams PA (1995) Implications of dynamically variable traits for identifying, classifying, and measuring direct and indirect effects in ecological communities. Am Nat 146:112-134

Behrens Yamada S, Boulding EG (1998) Claw morphology, prey size selection and foraging efficiency in generalist and specialist shellbreaking crabs. J Exp Mar Biol Ecol 220:191-211

Berger J, Swenson JE, Persson IL (2001) Recolonizing carnivores and naive prey: conservation lessons from pleistocene extinctions. Science 291:1036-1039

Blackburn TM, Gaston KJ (2005) Biological invasions and the loss of birds on islands. In: Sax D, Gaines SD, Stachowicz J (eds) Exotic species: a source of insight into ecology, evolution, and biogeography. Academic Press, New York, pp 85-110

Boulding EG, Hay TK (1984) Crab response to prey density can result in density dependent mortality of clams Protothaca-Staminea. Can J Fish Aquat Sci 41:521-525

Brown HM, Briden A, Stokell T, Griffin FJ, Cherr GN (2004) Thermotolerance and Hsp70 profiles in adult and embryonic California native oysters, Ostreola conchaphila (Carpenter, 1857). J Shellfish Res 23:135-141

Carpenter SR, Kitchell JF, Hodgson JR (1985) Cascading trophic interactions and lake productivity. Bioscience 35:634-639

Colautti RI, Ricciardi A, Grigorovich IA, MacIsaac HJ (2004) Is invasion success explained by the enemy release hypothesis? Ecol Lett 7:721-733

Cox JG, Lima SL (2006) Naivete and an aquatic-terrestrial dichotomy in the effects of introduced predators. Trends Ecol Evol 21:674680

Cunningham PN, Hughes RN (1984) Learning of predatory skills by shorecrabs Carcinus-Maenas feeding on mussels and dogwhelks. Mar Ecol Prog Ser 16:21-26

Darwin CR (1859) The origin of species. Literary Classics, New York

deRivera CE, Ruiz GM, Hines AH, Jivoff P (2005) Biotic resistance to invasion: native predator limits abundance and distribution of an introduced crab. Ecology 86:3364-3376

Elton CS (1958) The ecology of invasions by animals and plants. University of Chicago Press, Chicago, Illinois

Estes JA, Palmisano JF (1974) Sea otters-their role in structuring nearshore communities. Science 185:1058-1060

Federighi H (1931) Salinity death-points of the oyster drill snail, Urosalpinx cinerea Say. Ecology 12:346-353

Garth JS, Abbott DP (1980) Brachyura: the true crabs. In: Morris RH, Abbott DP, Haderlie EC (eds) Intertidal invertebrates of California. Stanford University Press, Stanford, pp 594-631

Gastreich KR (1999) Trait-mediated indirect effects of a theridiid spider on an ant-plant mutualism. Ecology 80:1066-1070 
Grabowski JH, Hughes AR, Kimbro DL, Dolan MA (2005) How habitat setting influences restored oyster reef communities. Ecology 86:1926-1935

Grosholz E (2002) Ecological and evolutionary consequences of coastal invasions. Trends Ecol Evol 17:22-27

Grosholz ED, Ruiz GM (1996) Predicting the impact of introduced marine species: lessons from the multiple invasions of the European green crab Carcinus maenas. Biol Conserv 78:59-66

Gross WJ (1957) An analysis of response to osmotic stress in selected decapod Crustacea.Biol Bull 112:43-62

Hairston NG, Smith FE, Slobodkin LB (1960) Community structure, population control, and competition. Am Nat 94:421-425

Hanks JE (1957) The rate of feeding of the common oyster drill, Urosalpinx cinerea (SAY), at controlled water temperatures. Biol Bull 112:330-335

Hellberg ME, Balch DP, Roy K (2001) Climate-driven range expansion and morphological evolution in a marine gastropod. Science 292:1707-1710

Hughes RN, Elner RW (1979) Tactics of a predator, Carcinus-Maenas, and morphological responses of the prey, Nucella-Lapillus. J Anim Ecol 48:65-78

Jackson JBC et al (2001) Historical overfishing and the recent collapse of coastal ecosystems. Science 293:629-637

Kaiser MJ, Hughes RN, Gibson RN (1993) Factors affecting diet selection in the shore crab, Carcinus-Maenus $(\mathrm{L})$. Anim Behav 45:83-92

Kimbro DL, Grosholz ED (2006) Disturbance influences oyster community richness and evenness, but not diversity. Ecology 87(9):2378-2388

Kraemer GP, Sellberg M, Gordon A, Main J (2007) Eight-year record of Hemigrapsus sanguineus (Asian shore crab) invasion in western long island sound estuary. Northeastern Naturalist 14:207-224

Largier JL, Hollibaugh JT, Smith SV (1997) Seasonally hypersaline estuaries in Mediterranean-climate regions. Estuar Coast Shelf Sci 45:789-797

Lubchenco J (1978) Plant species-diversity in a marine inter-tidal community-importance of herbivore food preference and algal competitive abilities. Am Nat 112:23-39

McDonald PS, Jensen GC, Armstrong DA (1998) Green crabs and native predators: possible limitation on the West Coast Invasion. Abstr J Shellfish Res 17: 1283

Myers RA, Baum JK, Shepherd TD, Powers SP, Peterson CH (2007) Cascading effects of the loss of apex predatory sharks from a coastal ocean. Science 315:1846-1850

Paine RT (1980) Food Webs-linkage, interaction strength and community infrastructure-the 3rd tansley lecture. J Anim Ecol 49:667-685

Parker JD, Burkepile DE, Hay ME (2006) Opposing effects of native and exotic herbivores on plant invasions. Science 311:1459-1461

Power ME, Matthews WJ, Stewart AJ (1985) Grazing minnows, piscivorous bass, and stream algae-dynamics of a strong interaction. Ecology 66:1448-1456

Preisser EL, Bolnick DI, Benard MF (2005) Scared to death? The effects of intimidation and consumption in predator-prey interactions. Ecology 86:501-509

Quinn GP, Keough MJ (2002) Experimental design and data analysis for biologists. In: Experimental design and data analysis for biologists, Cambridge University Press, pp i-537
Ripple WJ, Beschta RL (2007) Hardwood tree decline following large carnivore loss on the Great Plains, USA. Front Ecol Environ 5:241-246

Ruiz GM, Fofonoff PW, Carlton JT, Wonham MJ, Hines AH (2000) Invasion of coastal marine communities in North America: apparent patterns, processes, and biases. Annu Rev Ecol Syst 31:481531

Sax DF, Gaines SD (2003) Species diversity: from global decreases to local increases. Trends Ecol Evol 18:561-566

Scheiner SM, Gurevitch J (2000) Design and analysis of ecological experiments. Chapman \& Hall, New York

Schmitz OJ (2008) Effects of predator hunting mode on grassland ecosystem function. Science 319:952-954

Schmitz OJ, Krivan V, Ovadia O (2004) Trophic cascades: the primacy of trait-mediated indirect interactions. Ecol Lett 7:153-163

Sih A (1985) Evolution, predator avoidance, and unsuccessful predation. Am Nat 125:153-157

Silliman BR, Bertness MD (2002) Atrophic cascade regulates salt marsh primary production. Proc Natl Acad Sci USA 99:10500 10505

Smith LD (2004) Biogeographic differences in claw size and performance in an introduced crab predator Carcinus mamas. Mar Ecol Prog Ser 276:209-222

Smith SV, Hollibaugh JT, Vink S (1989) Tomales Bay, California-a case for carbon-controlled nitrogen cycling. Limnol Oceanogr 34:37-52

Stachowicz JJ (2001) Mutualism, facilitation, and the structure of ecological communities. Bioscience 51:235-246

Strauss SY, Lau JA, Schoener TW, Tiffin P (2008) Evolution in ecological field experiments: implications for effect size. Ecol Lett 11:199-207

Strong DR (1992) Are trophic cascades all wet-differentiation and donor-control in speciose ecosystems. Ecology 73:747-754

Trussell GC, Ewanchuk PJ, Bertness MD (2002) Field evidence of trait-mediated indirect interactions in a rocky intertidal food web. Ecol Lett 5:241-245

Underwood AJ (1981) Techniques of analysis of variance in experimental marine biology and ecology. Oceanogr Mar Biol Annu Rev 19:513-605

Vermeij GJ (1982a) Environmental change and the evolutionary history of the periwinkle (Littorina littorea) in North America. Evolution 36:561-580

Vermeij GJ (1982b) Unsuccessful predation and evolution. Am Nat 120:701-720

Vermeij GJ (2001) Community assembly in the sea geologic history of the living shore biota. In: Bertness MD, Gaines SD, Hay ME (eds) Marine community ecology. Sinauer Associates, Sunderland, pp 39-60

Werner EE, Peacor SD (2003) A review of trait-mediated indirect interactions in ecological communities. Ecology 84:1083-1100

Williams AB (1984) Shrimps, lobsters and crabs of the Atlantic coasts of the eastern United States, Maine to Florida. Smithsonian Institution Press, Washington, DC

Worm B et al (2006) Impacts of biodiversity loss on ocean ecosystem services. Science 314:787-790 